\title{
MUNCHAUSEN SYNDROME BY PROXY
}

\author{
Roy Meadow
}

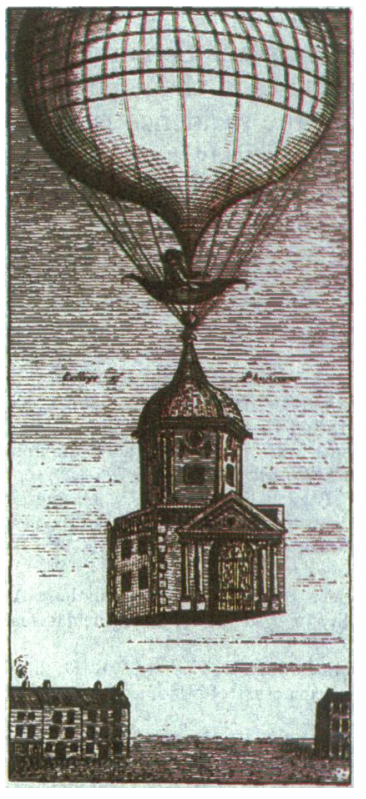

RAISINO THE COLLEOE OF PHYSICIANS

Baron von Munchausen, born in 1720, was a German mercenary and $a$ gifted raconteur. Richard Asher in 1951 dedicated the Munchausen syndrome to the memory of the baron because the patients had his characteristic of travelling widely and telling false stories.

The picture shows Baron von Munchausen raising the College of Physicians of London into the air for three months, during which the health of its patients was never better

Professor Roy Meadow, FRCP, is head of the department of paediatrics and child health, St James's University Hospital, Leeds, and has edited this ABC series.
Munchausen syndrome by proxy was used first in 1977 to describe children whose mothers invented stories of illness about their child and substantiated the stories by fabricating false physical signs.

The Munchausen syndrome is applied to adults who invent false stories of illness about themselves, thereby incurring needless investigations and treatments. For children affected by the Munchausen syndrome by proxy the proxy is the mother, who provides the false information. Child abuse results partly from the direct actions of the mother - for example, giving drugs to make the child unconscious - and partly from those of doctors, who arrange invasive investigations or needless treatments for a child at the mother's instigation.

In the past 10 years the boundaries of this type of abuse have been found to be wide and to overlap with other forms of abuse; it manifests in four main ways: perceived illness, doctor shopping, enforced invalidism, and fabricated illness.

\section{Perceived illness}

Anxious parents may worry needlessly that their healthy child is ill. A mother who is inexperienced, under stress, lonely, or herself ill is all the more likely to perceive symptoms in her child that others do not observe. The child is taken to doctors, perhaps on many occasions, if she cannot be reassured. Often the child will have unpleasant investigations and treatments because of the mother's insistence. Most doctors, however, would not classify this process as child abuse unless the mother's persistence and refusal to accept normal results was excessive and the quality of the child's life was being seriously impaired.

\section{Doctor shopping}

Some parents shop around or seek help from a succession of different doctors. They may do this within the NHS or privately by paying for consultations. They persist in claiming that their healthy child is ill, and as each doctor in turn refuses further investigation they consult yet another doctor. The result for the child is a series of repetitive investigations and unpleasant venepunctures and a body that has been thoroughly irradiated and biopsied. When a parent's conviction about illness reaches these delusional proportions it results in child abuse.

\section{Enforced invalidism}

Some parents who have an ill or disabled child seek to keep the child ill, increase the degree of disability, or ensure that the child is regarded as incapacitated (when he or she is not). Thus the parents of a child with normal intelligence who has difficulty with spelling may insist that their child is mentally disabled and persuade the education authorities to accept the child into a special school. Alternatively, parents of children with a mild hemiplegia may insist that they spend their time in a wheelchair and bring them up to believe that they cannot walk, when they can.

The link with school refusal and school phobia is obvious. In many cases the child is being brought up to believe that he or she is ill and to miss school. Normally when a child is absent from school for an extended time the education authorities have the power to force the parents to return the child to education, but the difficulty for the education authorities is that these children have a genuine medical problem and the parents can persuade the education authorities that the disability from the child's illness is greater than it is; teaching or a special school may then be arranged.

\section{Dealing with perceived illness, doctor shopping, and enforced invalidism}

When dealing with perceived illness, doctor shopping, or enforced invalidism the doctor should bear in mind that these types of behaviour are an extension of the usual way that many parents behave when their child is ill. As with all forms of child abuse, it is the degree of abuse that matters. For a worried parent to seek a second or third specialist opinion is reasonable: to seek a 22nd opinion is not. As doctors, we have to listen carefully to parents' worries and to believe them when they say that their child is ill. We have to work within the framework of parents' expectations and experience of health to help them to come to understand and accept their child's behaviour and health. No one will blame a mother who keeps her child away from school an extra day or two because her child has a chronic illness or disability. Most of us accept the strategies that parents adopt to deal with chronic illness within their family, even when we do not agree with them: if the mother believes that a special diet will lessen the number of seizures of her epileptic child then it is unreasonable to interfere unless the diet is definitely nutritionally unsound or very inconvenient. If the child is 
being forced to sleep on the back of an upturned cupboard enclosed in aluminium foil to avoid suspected allergens, however, the strategy amounts to child abuse and interference is necessary.

With such families early cooperation with health visitors and also social services may be helpful. For hospital doctors close consultation with the general practitioner is needed because only the general practitioner may be aware of the many other specialists previously consulted. If the parents cannot be dissuaded by careful and sympathetic help from their perceptions and actions that are harming their child then child abuse procedures should be invoked.

\section{Fabricated illness}

Fabricated or factitious illness results from parents who lie to the doctor about their child's health and from those who fabricate physical signs or alter health records. Some parents do all these things, but it can be equally serious for the child if the parent merely relates persistently and realistically a convincing history of illness for example, many epileptic seizures each week for the story alone will cause the doctor to embark on detailed investigations and prescribe anticonvulsant treatment. Parents invent the false illness while the child is young - usually starting within the first two years. They may continue and intensify the story of illness as the years pass. If the deception is not uncovered before the child is of school age some children will

\section{Fabricated illnesses}

False sign
Seizures, apnoea,
and drowsiness
Bleeding
(haematuria,
haematemesis,
etc)

Fever

\section{Diarrhoea}

Vomiting

Hypertension

Rashes

Renal stone

Faeculent vomits

Failure to thrive and thinness

\section{Cause}

Poisons, suffocation, pressure on carotid sinus

Blood from mother (particularly vaginal tampon), raw meat, or child added to sample from child or smeared around child's nose, vulva, etc

Colouring agents added to sample or smeared on to child

Warfarin administration

Warming thermometer

Altering temperature chart

Injections of contaminated material into

Repetitive injections of antigenic material

Laxatives

Mechanically induced

Salt or emetic poisoning

Altering blood pressure chart or instructions concerning size of cuff for blood pressure estimation

Scratching the skin to cause blisters Caustics and dyes

Addition of stone to child's urine to which blood has previously been added

Making child vomit and stirring in faeces

Withholding food

If in hospital and child is parenterally fed interfering with treatment and sucking back stomach contents through nasogastric tube child's vein participate in the deception. The mother teaches the child to trick the doctors and to lie. Some children subsequently have become independent illness addicts and have grown up to have the Munchausen syndrome.

There are five main consequences for children who are falsely labelled as ill.

(1) They will receive needless and harmful investigations and treatments.

(2) A genuine disease may be induced by the mother's actions - for example, renal failure as a result of regular injections of immunisation agents given to cause fever.

(3) They may die suddenly as a result of the mother misjudging the degree of insult. Mothers who, for example, partially suffocate their children to cause unconsciousness may smother the child for too long thereby causing brain damage or death.

(4) They may develop chronic invalidism. The child accepts the illness story and believes himself to be disabled, unable to attend school, to work, or even to walk.

(5) They may develop Munchausen syndrome as an adult - the children have learnt and then taken over the lying behaviour of their mother.

The stories of false illness usually concern the common chronic disorders of childhood: recurrent seizures, diarrhoea and vomiting, rashes, allergy, and fevers. Often they include more dramatic items such as recurrent bleeding.

In many instances the mother confirms the false history with false signs. The table lists some false signs together with the usual ways in which they are caused.

The consequences may be serious: some children have been in hospital for more than 18 months, during which their mothers have continued to lie and to fabricate signs; others have been absent from school for more than two years or have had lengthy periods of parenteral feeding, intravenous drug treatments, and large amounts of inappropriate drugs, including corticosteroids and cytotoxic agents.

In nearly all cases the mother is the deceiver: the father does not know what is going on. The mother tends to be the dominant person in the marriage and to be more intelligent and capable than her husband. The husband tends to be in the background, getting on with his own life and unsupportive of his wife's needs. The mothers often have had a difficult childhood themselves, and many have worked as nurses. About a fifth of the mothers are personal illness addicts and are notorious for presenting with unexplained illnesses.

The mothers usually keep to one general practitioner and when referred to hospital to one specialist. The referrals to other specialists come from the general practitioner or the hospital specialist. For the more complicated cases the children are transferred from centre of excellence to centre of excellence, where they undergo repetitive examination. The mother thrives on this, accompanying the child to the different hospitals, and is an avid consumer of good facilities for resident mothers.

Many of the mothers have had formal 


\section{Action on suspicion of factitious illness}

- Check history in detail-obtain verification of events alleged to have occurred in presence of third parties

- Seek temporal association between events and mother's presence

- Check personal, social, and family history-often the mother will have lied about them

- Contact other family members and doctors or health workers concerned

- Seek a motive-What is the mother gaining from making her child ill?

In hospital

- Secure and verify charts and records

- Retain and analyse samples-for example, blood and urine samples for toxicology

- Increase surveillance

- Participate with social services

- Exclude mother (aim for voluntary exclusion, though legal enforcement may be required)

psychiatric assessment and most are considered not to have a mental illness, though they have a personality disorder.

\section{Warning signs}

In a minority of families other siblings are similarly affected and in a few families there has been non-accidental injury or unexplained death of other children.

Some of the warning signs that should alert a doctor to fabricated illness are listed below.

(1) The illness is unexplained, prolonged, or extremely rare.

(2) The symptoms and signs have a temporal association with the mother's presence. They may also be incongruous - for example, blood stained vomit from a child who is pink and laughing and has a full volume pulse.

(3) The mother is a hospital addict and more anxious to impress the doctor than she is worried about her child's illness.
(4) The treatment prescribed is ineffective and not tolerated.

(5) In the family there are multiple illnesses and similar symptoms in other members of the family.

\section{Motive}

The motives vary. For most mothers there is personal gain in terms of status, contacts with helpful doctors, nurses, and social workers, financial benefits, contact with other mothers and a different society in hospital, escape from an unhappy marriage, or the capture of an absent husband to share a problem. After talking with many of these mothers my main impression is of their immense selfishness: they are able to do horrific things to children because of their own unhappiness and to satisfy their own needs. In a minority, particularly those who indulge in suffocation or poisoning, there commonly is envy of, and violence and hatred towards, the abused child.

\section{Action and reaction}

At one end of its range fabricated illness is as serious as any other type of abuse and calls for prompt liaison with social services, and sometimes the police, to protect the child. It is, however, important not to overreact just because a mother is lying or fabricating signs. Sometimes a mother may add blood to her child's urine or alter a temperature chart to dissuade the doctors from discharging her child from hospital before she is sufficiently reassured and ready to cope. Such minor events are common and should be sorted out sympathetically and promptly in a way that dissuades the mother from giving false histories or fabricating signs again.

The doctor discovering deception has to stand back for a moment and work out exactly how much the child is being harmed by the mother's direct and indirect actions and then discuss those factors with social services.

\section{MATERIA PARAMEDICA}

\section{Now it tickles; now it doesn't: psychogenic variations in the perception of tactile stimuli}

Everyone who has frolicked with children (and who has not?) knows that if the children are tickled in the ribs they are reduced to helpless screaming laughter and violent efforts at avoidance. Those who can remember being tickled in the ribs will know that by an identical action you cannot tickle yourself in the ribs. That action merely yields a bland sensation of pressure. How is it that the same stimulus - namely, firm finger tip pressure on the periosteum of the ribs-produces an entirely different response, depending on whether it is applied by self or by another person? By the same token, the sensation induced subjectively feels entirely different. The evolutionary survival value of the difference is plain. But what is the explanation of the difference in a psychoneurological sense?

An almost identical difference in response, subjective and objective, is obtained by abruptly applying finger tip pressure to the distal fasciae of the thigh. To evoke this reaction place your hand palm down, over the distal thigh anteriorly, just above the knee; thumb on one side, index and middle fingers on the other. It is as well to choose a good friend as subject, and to obtain prior consent for "a harmless little experiment." Abruptly press the thumb and finger tips firmly into the thigh with a squeezing action. The subject feels an intense and unbearable tickle, and takes violent avoiding action. Ask the subject to repeat the manoeuvre on him (or her) self. There is then merely a bland feeling of pressure. Again, why the difference? In a clinical context one must be aware of this phenomenon when palpating the abdomen of young patients, otherwise a rigid abdominal wall will resist the examining hand. It was my practice with youngsters to interpose a layer of undergarment between hand and abdomen and to remove it when mutual confidence was achieved.

A similar situation pertains to the pharynx. A foreign body, if accepted as food, induces no nausea and is swallowed. A non-food foreign body, by contrast, such as a tongue depressor, or a mirror pressed against the soft palate during indirect laryngoscopy, is prone to cause immediate nausea and retching (which for some reason is called "gagging" in this context). This is almost inevitable in children and young adults, but the response wanes with aging. Now, every good laryngologist knows (and every good physician should know) that the gagging reflex can be mitigated, and even suppressed, if the doctor distracts the patient's attention from what is happening in the throat by maintaining a running patter of encouraging remarks. Here again we have the seeming paradox that the response to a tactile stimulus applied to the retro-oral and pharyngeal mucosa differs according to the mental attitude of the subject. Not only is the response different, the stimulus feels different. Less predictably, a light cutaneous touch may be perceived with an additional "thrill" in a potentially erotic context.

What is the neurological basis for these differences? The psyche seems to mediate different neurological pathways according to variations in environmental circumstances. If so, how? - BERNARD J FREEDMAN 